\title{
Purification of Anthocyanins with o-Dihydroxy Arrangement by Sorption in Cationic Resins Charged with Fe(III)
}

\author{
Araceli Castañeda-Ovando, Carlos Andrés Galán-Vidal, \\ Elizabeth Contreras-López, and Ma. Elena Páez-Hernández \\ Academic Area of Chemistry, Autonomous University of Hidalgo State, 42184 Mineral de la Reforma, HGO, Mexico \\ Correspondence should be addressed to Araceli Castañeda-Ovando; ovandoa@uaeh.edu.mx
}

Received 26 May 2014; Revised 7 August 2014; Accepted 8 August 2014; Published 11 September 2014

Academic Editor: Hasan Uslu

Copyright (c) 2014 Araceli Castañeda-Ovando et al. This is an open access article distributed under the Creative Commons Attribution License, which permits unrestricted use, distribution, and reproduction in any medium, provided the original work is properly cited.

\begin{abstract}
In the present work, a new purification method of anthocyanins with o-dihydroxy arrangement is proposed. This method is based on a ligand-exchange mechanism, using a cationic exchange resin loaded with metallic ions in order to increase the affinity of the resin to the anthocyanin(s) with o-dihydroxy arrangement. This method was used to purify the main anthocyanin (cyanidin-3glucoside; Cy-3-glc) from the anthocyanic methanolic extract of blue corn. The best sorption result was using Fe(III) in its ion form. The purification procedure begins with the formation of a metal-anthocyanin complex (Cy-3-glc-Fe) which was optimal at $\mathrm{pH} 5$, followed by a $\mathrm{NaOH} 0.1 \mathrm{M}$ elution process in order to eliminate anthocyanins without o-dihydroxy arrangement, sugars, and organic acids. Finally, the pure anthocyanin is obtained by adding $\mathrm{HCl} 0.1 \mathrm{M}$ which breaks the metal-anthocyanin complex.
\end{abstract}

\section{Introduction}

Anthocyanins are the most important pigments on vascular plants and are responsible for the bright orange, pink, red, violet, and blue colors in the flowers and fruits of some plants. They are harmless and easy to incorporate into aqueous systems. These characteristics make them interesting to be used as natural hydrosoluble colorants [1]. Another important anthocyanins property is their high antioxidant activity, which plays a significant role in the prevention of neuronal, chronic degenerative, and cardiovascular diseases, such as cancer, arteriosclerosis, and diabetes [2].

The content of these pigments is low. Fresh fruits exhibit a range of $100-5000 \mu \mathrm{g} / \mathrm{g}$, depending on the species [3]. In cereals such as rice, maize, wheat, and barley, the contents are in the range of 7-3000 $\mu \mathrm{g} / \mathrm{g}$ [4].

Recently, these natural compounds have been increasing their economic importance in the industrial scope of the natural colorants field, and more specifically in the anthocyanins field. Nowadays, it is necessary more than ever to count on alternatives that improve the yield of the extraction process and to find simple and economical purification methodologies that can be applied in the industry $[5,6]$.
Due to the polar nature of anthocyanins, the most used extraction methods currently consist of extractions with aqueous sulfurated solutions or with polar acidified solvents [7]. Methanol and ethanol are the most used solvents in anthocyanins extraction, being the first one the most efficient at $20 \%$ [1]. However, the proposed extraction methods are not very selective and a great number of sample components are coextracted, such as sugar or organic acid [8]. Thus, when the extraction process is completed, it is essential to implement purification techniques in order to isolate the anthocyanin(s) of interest.

For the purification of anthocyanins diverse analytical techniques have been proposed, from solid phase extractions (SPE) [9-11] to the use of chromatographic techniques, such as countercurrent chromatography (CCC) [12], medium pressure liquid chromatography (MPLC) [13], and high performance liquid chromatography (HPLC) [14-19].

Usually SPE is carried out in $\mathrm{C}_{18}$ or Sephadex cartridges. In this case the anthocyanins are bounded strongly to these adsorbents by their hydroxyl groups. After the adsorption they are separated from other compounds by consecutive increases of the polarity of different solvents [20]. 


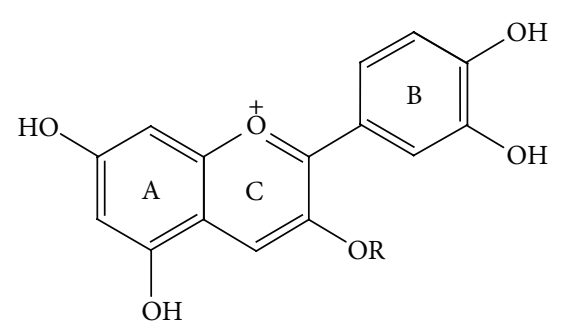

(a)

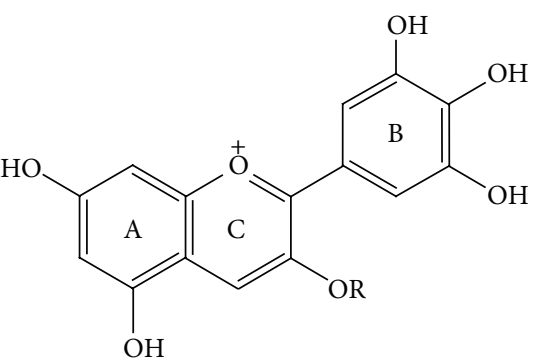

(b)<smiles>[R2]c1cc2c(O)cc(O)cc2[o+]c1-c1cc(O)c(O)c(OC)c1</smiles>

(c)

FIGURE 1: Chemical structures of anthocyanins with o-dihydroxy arrangement; (a) cyanidin (Cy), (b) delphinidin (Dp) y, (c) petunidin (Pt). $\mathrm{R}=$ monosaccharide or disaccharide.

CCC and MPLC are used as purification methods with later analysis by HPLC for the structural elucidation, with the advantage that it reduces the separation time and the cost of the mobile phase [1]. HPLC has been reported more frequently as the separation method for anthocyanins. However, it is required to spend a great amount of solvents and time to obtain a significant amount of purified pigment.

In the search of simple and economic purification methodologies, alcohol eluents such as ethanol or propanol are used in the adsorption-desorption of anthocyanins in styrene-divinylbenzene adsorbents. This is one of the purification methods that have recently been explored [5]. The recovery percentage obtained ranged from 96 to $100 \%$ of total anthocyanins. Although the use of cationic exchange resins could be an interesting alternative of purification, there are not reports about it. It is probably due to the flavylium ion being such a polar molecule that the resin presents a very strong adsorption.

Considering that the anthocyanins and anthocyanidins with o-dihydroxy arrangement are very good at forming metal complexes [21, 22] (Figure 1), in the present work a simple and economic purification method of anthocyanins with o-dihydroxy arrangement in ring B (Figure 1) is reported. The method is based on the ligand-exchange mechanism on a $\mathrm{Fe}(\mathrm{III})$-loaded cation exchange resin.

\section{Materials and Methods}

2.1. Reagents. All chemicals were used as received and were analytical grade. Methanol HPLC grade $(\geq 99.9 \%)$ was purchased from Mallinckrodt Baker (NJ, USA). $\mathrm{HCl}$ (36-38\%), $\mathrm{NaOH}\left(\geq 98 \%\right.$, pellets), $\mathrm{FeCl}_{3} \cdot 6 \mathrm{H}_{2} \mathrm{O}$ (97\%), $\mathrm{Fe}\left(\mathrm{NH}_{4}\right)_{2}\left(\mathrm{SO}_{4}\right)_{2} \cdot 6 \mathrm{H}_{2} \mathrm{O} \quad(\geq 98 \%), \quad \mathrm{CuSO}_{4} \cdot 5 \mathrm{H}_{2} \mathrm{O} \quad(\geq 98 \%)$, $\mathrm{CaCl}_{2}(\geq 97 \%), \mathrm{MgSO}_{4} \cdot 7 \mathrm{H}_{2} \mathrm{O}(\geq 98 \%)$, acetic acid ( $\left.\geq 99.7 \%\right)$, sodium acetate $(\geq 99 \%)$, strong acid cationic resin DOWEX50W-X8 ( $\mathrm{H}^{+}$form), $\mathrm{H}_{3} \mathrm{BO}_{3}(\geq 99.5 \%)$, and $\mathrm{H}_{3} \mathrm{PO}_{4}$ (85\%) were purchased from Sigma-Aldrich (MO, USA). Deionized water $(18.2 \mathrm{M} \Omega \mathrm{cm})$ from a Milli-Q equipment of Millipore (MA, USA) was used to prepare all the solutions. One batch of $10 \mathrm{~kg}$ pigmented blue corn was kindly donated by Colegio de Postgraduados (Mexico).
2.2. Apparatus. UV-vis spectra were obtained in a Lambda 40 spectrophotometer from Perkin-Elmer at a scanning speed of $60 \mathrm{~nm} \mathrm{~min}^{-1}$. HPLC analyses were performed on a Perkin Elmer Series 200 liquid chromatograph from Perkin Elmer (MA, USA), equipped with a UV-vis detector at $515 \mathrm{~nm}$ and manual injector (sample volume of $50 \mu \mathrm{L}$ ).

2.3. Extraction Procedure. The crude extract was obtained by stirring $50 \mathrm{~g}$ of sample (grounded grain of pigmented corn) with five portions ( $250 \mathrm{~mL}$ each one) of $2 \%(\mathrm{v} / \mathrm{v})$ $\mathrm{HCl}$-methanol solution at $4^{\circ} \mathrm{C}$ for $2 \mathrm{~h}$. The raw extract was concentrated under vacuum in a rotary evaporator from Büchi (Buch, Switzerland) at room temperature to reach a final volume of $10 \mathrm{~mL}$. Later on, a liquid-liquid extraction (LLE) was carried out with diethyl ether (2 extractions with $25 \mathrm{~mL}$ of solvent each one) to remove lipidic material or liposoluble substances contained in the raw extract [23]. The extract was preserved in methanolic solution for the following experiments.

2.3.1. Preparation of Solutions. For this experiment the following solutions were prepared: $\mathrm{HCl}(1$ and $0.1 \mathrm{~mol}$ $\left.\mathrm{L}^{-1}\right), \mathrm{NaOH}\left(0.1\right.$ and $\left.0.01 \mathrm{~mol} \mathrm{~L}^{-1}\right), \mathrm{Fe}^{3+}\left(0.1 \mathrm{~mol} \mathrm{~L}^{-1}\right.$, from $\left.\mathrm{FeCl}_{3} \cdot 6 \mathrm{H}_{2} \mathrm{O}\right), \mathrm{Fe}^{2+}\left(0.1 \mathrm{~mol} \mathrm{~L}^{-1}\right.$, from $\mathrm{Fe}\left(\mathrm{NH}_{4}\right)_{2}\left(\mathrm{SO}_{4}\right)_{2}$. $\left.6 \mathrm{H}_{2} \mathrm{O}\right), \mathrm{Cu}^{2+}\left(0.1 \mathrm{~mol} \mathrm{~L}^{-1}\right.$, from $\left.\mathrm{CuSO}_{4} \cdot 5 \mathrm{H}_{2} \mathrm{O}\right), \mathrm{Ca}^{2+}$ $\left(0.1 \mathrm{~mol} \mathrm{~L}^{-1}\right.$, from $\left.\mathrm{CaCl}_{2}\right)$, and $\mathrm{Mg}^{2+}\left(0.1 \mathrm{~mol} \mathrm{~L}^{-1}\right.$, from $\mathrm{MgSO}_{4} \cdot 7 \mathrm{H}_{2} \mathrm{O}$ ). All the solutions for the different metals were prepared in $\mathrm{HCl} 0.1 \mathrm{~mol} \mathrm{~L}^{-1}$. In order to prepare the solution of the extract at different $\mathrm{pH}$ values for the sorption experiments, five replicates of $1 \mathrm{~mL}$ of the semipurified extract were taken, each one of these was diluted at $25 \mathrm{~mL}$ and then $\mathrm{pH}$ was adjusted with a $\mathrm{HCl} 0.1 \mathrm{M}$ solution from $\mathrm{pH} 1$ to 2 , and with a buffer acetate solution from $\mathrm{pH} 3$ to 5. The buffer acetate solution $\left(5 \times 10^{-2} \mathrm{~mol} \mathrm{~L}^{-1}, \mathrm{pH} 5.0\right)$ was prepared from acetic acid and sodium acetate.

2.3.2. Resin Preparation. A strong acid cationic resin DOWEX-50W-X8 $\left(\mathrm{H}^{+}\right.$form) was used for all sorption experiments. The procedure carried out for each one of the metallic ions consisted of the following steps: (1) conditioning of the resin by stirring it with $\mathrm{HCl} 1 \mathrm{~mol} \mathrm{~L}^{-1}$ 
solution during 1 hour with the purpose of having it in its acidic form; (2) washing of the resin with distilled water until residual $\mathrm{pH}$ was 7 ; and (3) conditioning of the resin for each one of the metallic ions $\left(\mathrm{Fe}^{3+}, \mathrm{Fe}^{2+}, \mathrm{Cu}^{2+}, \mathrm{Ca}^{2+}\right.$ and $\left.\mathrm{Mg}^{2+}\right)$, by stirring it with $0.1 \mathrm{~mol} \mathrm{~L}^{-1}$ of the metal solution for 30 minutes in order to load the resin on each one of its cationic forms.

2.3.3. Sorption Experiments. Five resin samples loaded with different ions $\left(\mathrm{Fe}^{3+}, \mathrm{Fe}^{2+}, \mathrm{Cu}^{2+}, \mathrm{Ca}^{2+}\right.$, and $\left.\mathrm{Mg}^{2+}\right)$ were weighted ( $0.2 \mathrm{~g}$ approximately) and were placed in Pasteur pipettes simulating chromatographic columns. After that, $10 \mathrm{~mL}$ of extract solution at different $\mathrm{pH}$ values were added, following the next elution steps.

(1) No retained compounds were found on the first fraction obtained. In this stage the same solution served as eluent. A red color in the solution was observed.

(2) Afterwards, $2 \mathrm{~mL}$ of $\mathrm{NaOH} 0.1 \mathrm{~mol} \mathrm{~L}^{-1}$ solution was added as eluent, eluting those compounds that still remained in the column but that had not reacted with the metallic ion $\left(\mathrm{Fe}^{3+}, \mathrm{Fe}^{2+}, \mathrm{Cu}^{2+}, \mathrm{Ca}^{2+}\right.$, or $\left.\mathrm{Mg}^{2+}\right)$. A violet color was perceived in the resin.

(3) The last eluent added was $4 \mathrm{~mL}$ of $\mathrm{HCl} 0.1 \mathrm{~mol} \mathrm{~L}^{-1}$ solution, collecting all fractions obtained. Absorbance measurements were made in quartz cells with $10-\mathrm{mm}$ path length of Perkin Elmer.

2.3.4. Sorption Experiments at pH 5. According to previous results and research about complex $\mathrm{Fe}$ (III)-anthocyanin formation [22], it was decided to perform the same procedure described in Section 2.3.2. While using greater resin and extract amount at pH 5 and the loaded-resin with $\mathrm{Fe}$ (III) with the purpose of increasing the concentration of the eluted anthocyanin. An acetates solution was employed as buffer.

A solution containing $10 \mathrm{~mL}$ of extract and diluted at $50 \mathrm{~mL}$ with acetates buffer $\left(0.05 \mathrm{~mol} \mathrm{~L}^{-1}, \mathrm{pH}=5.0\right)$ was prepared. The elution procedure followed was the same as the one described in Section 2.3.3, but with modifications in the amount of resin (6.0027 $\mathrm{g}$ of dry resin) and loaded only with $\mathrm{Fe}^{3+} 0.1 \mathrm{~mol} \mathrm{~L}^{-1}$ solution (from $\mathrm{FeCl}_{3} \cdot 6 \mathrm{H}_{2} \mathrm{O}$, in $\mathrm{HCl}$ $0.1 \mathrm{~mol} \mathrm{~L}^{-1}$ ), since $\mathrm{Fe}(\mathrm{III})$ was the metal with the best sorption results.

The resin was packed in a chromatographic column (i.d. $2 \mathrm{~cm}$ ), adding $25 \mathrm{~mL}$ of extract solution, following the same elution steps described in Section 2.3.3, adding $12.5 \mathrm{~mL}$ of $\mathrm{NaOH} 0.1 \mathrm{~mol} \mathrm{~L}^{-1}$ solution and $25 \mathrm{~mL}$ of $\mathrm{HCl} 0.1 \mathrm{~mol} \mathrm{~L}^{-1}$, and collecting all fractions obtained.

The fractions collected at each elution step were analyzed by HPLC according to Castañeda-Ovando et al. [24], using an XTerra column from Waters $(250 \times 4.6 \mathrm{~mm}, 4 \mu \mathrm{m})$.

2.3.5. Acidity Constants of the Purified Anthocyanin. Determinations at different $\mathrm{pH}$ experimental values were carried out in the following fashion: for $\mathrm{pH} 1$ the adjustment was made with $\mathrm{HCl} 1 \mathrm{~mol} \mathrm{~L}^{-1}$ solution. For the range of $\mathrm{pH} 2-$ 11, a Britton-Robinson buffer $\left(\mathrm{H}_{3} \mathrm{BO}_{3} 0.1 \mathrm{~mol} \mathrm{~L}^{-1}, \mathrm{H}_{3} \mathrm{PO}_{4}\right.$ $0.1 \mathrm{~mol} \mathrm{~L}^{-1}$ and $\mathrm{CH}_{3} \mathrm{COOH} 0.1 \mathrm{~mol} \mathrm{~L}^{-1}$ ) was used adding $\mathrm{NaOH}$ until the required values were obtained. And for $\mathrm{pH} 12$ and 13 , the $\mathrm{pH}$ was adjusted with $\mathrm{NaOH} 0.01$ and $0.1 \mathrm{~mol} \mathrm{~L}^{-1}$ respectively.

The fractions obtained in the last elution step at $\mathrm{pH} 5$ were collected and 13 aliquots of $1 \mathrm{~mL}$ each one were diluted with buffer solution at a $\mathrm{pH}$ ranging from 1 to 13 . The UV-vis spectra of each solution were obtained in a spectral window of 200-600 nm.

\section{Results and Discussion}

The purification method of anthocyanins with o-dihydroxy arrangement consisted in loading a cationic exchange resin with different ions, which have been reported as producers of metallic o-dihydroxy anthocyanin complexes, such as $\mathrm{Fe}^{3+}, \mathrm{Fe}^{2+}, \mathrm{Cu}^{2+}, \mathrm{Ca}^{2+}$, and $\mathrm{Mg}^{2+}[22,25,26]$. Subsequently a ligand-exchange mechanism with the main anthocyanin present in pigmented corn (cyanidin-3-glucoside) was carried out. This method has been reported mainly for inorganic species sorption studies, such as the one with arsenic [27, 28] and it can be well applied to the purification of organic molecules.

3.1. pH Influence in the Anthocyanin Sorption. The influence of $\mathrm{pH}$ on the adsorption of anthocyanins was studied with the purpose of finding out which are the best conditions for the adsorption of these compounds and also to determine the adsorption capacity of the cationic exchange resin loaded with different ions.

Based on the acquired results, a new adsorption mechanism for the main anthocyanin in the resin was proposed. The elution order described in Section 2.3.3 was done according to observations made during the experimentation phase. The metal-anthocyanin complex was stable in basic media, whereas when added to acidic media the bond was broken and the typical anthocyanins coloration (red) was observed. This fact is corroborated with the research reported by Yoshida et al. [22]. The calculation of the distribution coefficient of each one of the metallic ions was made considering the ligand-exchange equilibrium that is carried out in the resin. For the case of the $\mathrm{Fe}^{3+}$ we have

$$
\mathrm{R}-\mathrm{Fe}^{3+}+\mathrm{Cy}-3-\mathrm{glc} \longrightarrow \mathrm{R}-\mathrm{Fe}^{3+}-\mathrm{Cy}-3-\mathrm{glc}+x \mathrm{H}^{+}
$$

where $\mathrm{R}=$ polymeric resin and Cy-3-glc = cyanidin-3glucoside (main anthocyanin).

Therefore the distribution coefficient is calculated in the following way:

$$
D=\frac{\mathrm{mmolCy}-3-\mathrm{glc} / \mathrm{g}_{\text {resin }}}{\mathrm{mmolCy}-3-\mathrm{glc}_{\text {solution }}} .
$$

The extraction percentage $(\% E)$ is given by the expression:

$$
\% E=\frac{D \times \mathrm{g}_{\text {resin }}}{D \times \mathrm{g}_{\text {resin }}+1} * 100 \text {. }
$$




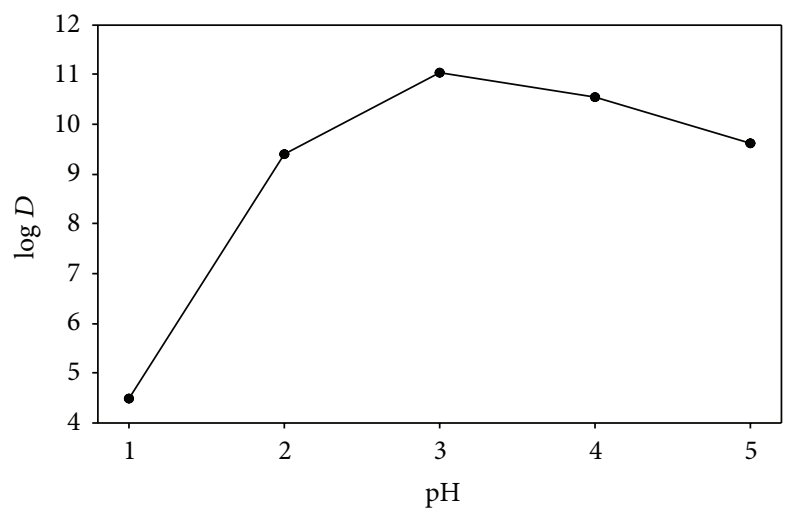

FIgURE 2: Relationship between distribution coefficient $(\log D)$ and $\mathrm{pH}$.

TABLE 1: Results of sorption anthocyanins processes in a cationic exchange resin loaded with different ions.

\begin{tabular}{lcc}
\hline Metal ion & $\log D$ & $\% E$ \\
\hline $\mathrm{Cu}(\mathrm{II})$ & $0.52-2.14$ & $7.93-79.81$ \\
$\mathrm{Ca}(\mathrm{II})$ & $0.54-1.74$ & $7.90-57.37$ \\
$\mathrm{Mg}(\mathrm{II})$ & $0.52-1.70$ & $11.12-55.29$ \\
$\mathrm{Al}(\mathrm{III})$ & $0.33-1.76$ & $4.38-56.48$ \\
$\mathrm{Fe}(\mathrm{II})$ & $0.60-1.30$ & $8.96-36.94$ \\
\hline
\end{tabular}

On the other hand, the distribution constant is expressed by the next equation:

$$
K=\frac{\overline{[\mathrm{Fe}-\mathrm{Cy}-3-\mathrm{glc}]} \times\left[\mathrm{H}^{+}\right]^{x}}{\overline{\left[\mathrm{Fe}^{3+}\right]} \times[\mathrm{Cy}-3-\mathrm{glc}]}
$$

where $\overline{[\mathrm{Fe}-\mathrm{Cy}-3-\mathrm{glc}]}, \overline{\left[\mathrm{Fe}^{3+}\right]}$ and $[\mathrm{Cy}-3$-glc $]$ are the concentrations of $\mathrm{Cy}-3-$ glc- $\mathrm{Fe}^{3+}$ and $\mathrm{Fe}^{3+}$ in resin and of $\mathrm{Cy}-3$-glc in solution, respectively.

Defining the distribution coefficient of the anthocyanin in the resin and in the solution we obtained:

$$
D=\frac{\overline{[C y-3-g l c]}}{[C y-3-g l c]} .
$$

Clearing (4) the anthocyanin concentration in the resin $(\overline{[\mathrm{Fe}-\mathrm{Cy}-3-\mathrm{glc}]}=\overline{[\mathrm{Cy}-3-\mathrm{glc}]})$ and replacing it in (5), we get

$$
D=\frac{K\left[\mathrm{Fe}^{3+}\right]}{\left[\mathrm{H}^{+}\right]^{x}} .
$$

In logarithmic terms

$$
\log D=x \mathrm{pH}+\log \left(K *\left[\mathrm{Fe}^{3+}\right]\right) .
$$

Equation (7) adopts the form of straight-line equation $(y=B x+A)$. Therefore the slope obtained will be numerically equal to the number of protons that have been liberated or required in the process.

The results found for $\mathrm{Cu}(\mathrm{II}), \mathrm{Ca}(\mathrm{II}), \mathrm{Mg}(\mathrm{II}), \mathrm{Al}(\mathrm{III})$, and Fe(II) were shown in Table 1 . These metal ions exhibit low values for $\log D$ and $\% E$ and do not have a linear behavior. Consequently, they were ruled out for further experimentation. These results can be attributed to the fact that the selectivity coefficients of each one of the resins used increase along its corresponding ion valence and size $\left(\mathrm{M}^{4+}>\right.$ $\mathrm{M}^{3+}>\mathrm{M}^{2+}>\mathrm{M}^{+}$) [29]. This shows that the greater the metallic ion concentration is in the resin, the more advantages found in the ligand-exchange mechanism that we propose.

Table 2 shows all of the data that were considered for the $D$ extraction percentage calculations in the method carried out with $\mathrm{Fe}^{3+}$. The initial concentration of total anthocyanins for all $\mathrm{pH}$ values was $1.57 \times 10^{-5} \mathrm{~mol} \mathrm{~L}^{-1}$ and was calculated using the spectral data for the Cy-3-glc $\left(\varepsilon_{510}=\right.$ $\left.26900 \mathrm{~cm}^{-1} \mathrm{~mol}^{-1} \mathrm{~L}\right)$. The initial concentration of Cy-3-glc was obtained by calculating the percentage of area under the chromatographic peak of this compound in its pure extract form. The percentage obtained was $34.32 \%$. Considering a $100 \%$ of area for the sum of all the peaks of the extract and a response factor of 1 , the concentration of Cy-3-glc obtained corresponds to $0.3432 *$ [Initial] and in every case the value found was $5.4 \times 10^{-6} \mathrm{~mol} \mathrm{~L}^{-1}$. According to the results observed at every range of $\mathrm{pH}$ the $\% E$ obtained was $>99 \%$.

Figure 2 represents the graphic $\log D$ versus $\mathrm{pH}$ in which it is observed that from $\mathrm{pH} 3$ on, the sorption process is less affected by $\mathrm{pH}$. With this consideration, a correlation between $\log D$ versus $\mathrm{pH}$ was done. Such results are shown further on.

In Figure 2 it is observed that $\mathrm{pH}$ range $1-3$ presents a positive slope and $\mathrm{pH}$ range $3-5$ a negative slope. Thus the correlations $\log D$ versus $\mathrm{pH}$ were done for these two intervals, finding that for the first of them 3 protons are released ( $\left.m=3.3, R^{2}=0.9224\right)$ and in the second range a proton is required so the reaction is carried out $(m=-0.7111$, $\left.R^{2}=0.9702\right)$. This in turn would give origin to the two proposed mechanisms.

Figure 3 shows the ligand-exchange mechanism for the Cy-3-glucoside sorption at the $\mathrm{pH}$ interval from 1 to 3 . This is the model adjusted to (7) considering a stoichiometry Fe: anthocyanin $1: 3$. In the proposed mechanism it is observed that there is a release of 3 protons which agrees with 
TABLE 2: Results of sorption anthocyanins processes in a cationic exchange resin loaded with $\mathrm{Fe}^{3+}$ ions.

\begin{tabular}{lccc}
\hline $\mathrm{pH}$ & {$[\mathrm{Cy}-3-\mathrm{glc}]_{\text {final }}, 10^{-6} \mathrm{~mol} \mathrm{~L}^{-1}$} & $m_{\text {resin }}(\mathrm{g})$ & $\log D$ \\
\hline 1 & 1.98 & 0.1530 & 4.49 \\
2 & 3.90 & 0.1725 & 9.41 \\
3 & 4.41 & 0.1758 & 11.04 \\
4 & 4.17 & 0.1694 & 10.54 \\
5 & 4.61 & 0.2161 & 9.62 \\
\hline
\end{tabular}<smiles>[R]C[R]([R])[R]</smiles>

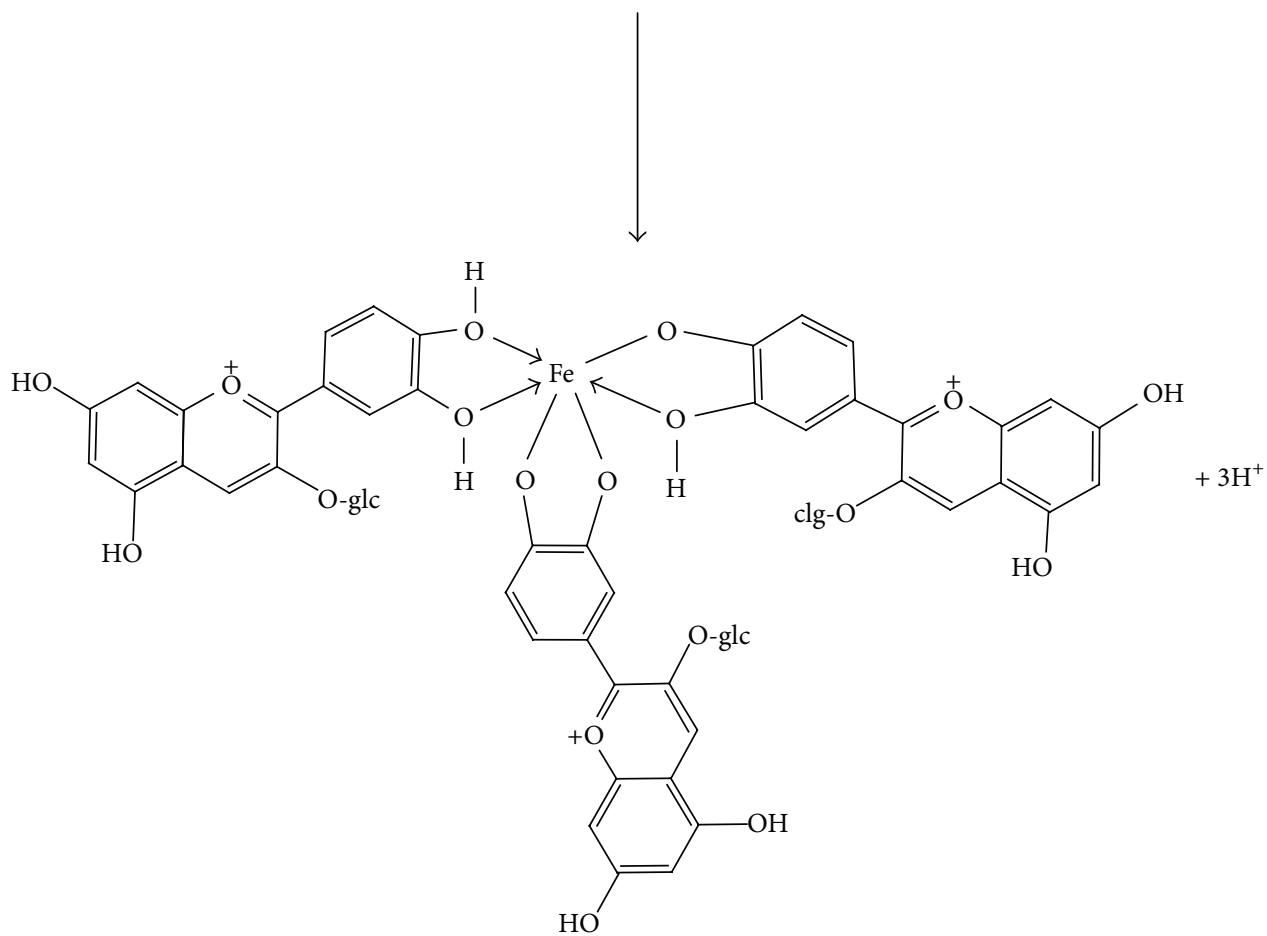

Figure 3: Ligand-exchange mechanism proposed for the Cy-3-glucoside sorption in cationic exchange resin loaded with $\mathrm{Fe}^{3+}$, in the $\mathrm{pH}$ range $1-3$, where glc $=$ glucoside and $\mathrm{R}=$ polymeric resin group (styrene-divinylbenzene)-sulfonate.

the correlation that is obtained from $\log \mathrm{D}$ versus $\mathrm{pH}$ for this interval.

Figure 4 shows the ligand-exchange mechanism proposed for the Cy-3-glucoside sorption in the 3-5 $\mathrm{pH}$ interval. The following considerations were done according to the model that better adjusts to (7): (a) that the stoichiometry Fe: anthocyanin was $1: 1$, (b) that $\mathrm{Fe}$ (III) was found in the second hydroxycomplex $\left[\mathrm{Fe}(\mathrm{OH})_{2}{ }^{+}\right]$, and (c) that the anthocyanin was in its anionic form (considering $\mathrm{p} K_{\mathrm{a}}$ 's calculated by Moncada et al. [25], $\mathrm{p} K_{\mathrm{a}}=3.34$ ).

This experiment was not done at higher $\mathrm{pH}$ values because the free anthocyanins in solution are not stable in this region.
3.2. Sorption Experiments at $p H 5$. According to Figure 2, the greatest value for $\log D$ is obtained at $\mathrm{pH} 3$. Nevertheless, it was decided to work at $\mathrm{pH} 5$ to secure the formation of the complex Fe(III)-Anthocyanin as stated by Yoshida et al. [22]. In addition, $\mathrm{Fe}$ (III) will be better linked to the resin (more stability) and $\log D$ does not change significantly with respect to $\mathrm{pH}=3$. The respective chromatograms for each one of the elutions were obtained from their HPLC analysis (Figure 5). In the chromatograms it is possible to observe that only one anthocyanin is eluted with $\mathrm{HCl} 0.1 \mathrm{~mol} \mathrm{~L}^{-1}$ (Fraction D).

These results indicate that only this anthocyanin is capable of forming a complex with $\mathrm{Fe}^{3+}$ and elute as an anthocyanin, given that the Fe-anthocyanin complex is dissociated 

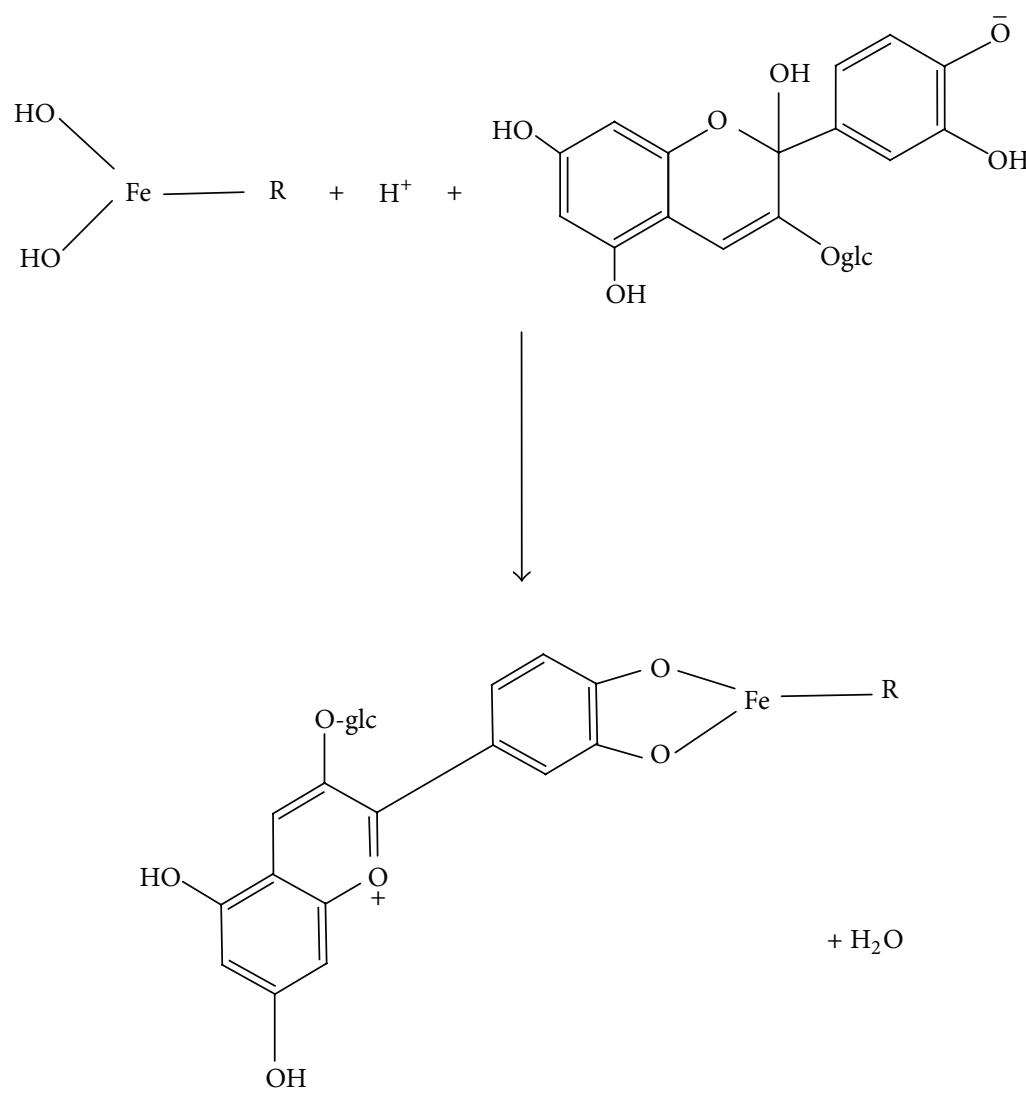

FIGURE 4: Exchange-ligand mechanism proposed for Cy-3-glucoside sorption in cationic exchange resin loaded with $\mathrm{Fe}^{3+}$ from $\mathrm{pH}$ 3, where: $\mathrm{glc}=$ glucoside and $\mathrm{R}=$ polymeric resin group (styrene-divinylbenzene)-sulfonate .

in acidic media and is stable in basic conditions; thus, it is still retained when the elution with $\mathrm{NaOH} 0.1 \mathrm{~mol} \mathrm{~L}^{-1}$ is carried out.

3.3. Acidity Constants Calculation. The $\mathrm{p} \mathrm{K}_{\mathrm{a}}$ 's calculations of the purified anthocyanin (cyanidin-3-glucoside) were made with the purpose of corroborating the presence of the purified anthocyanin considering $\mathrm{p} K_{\mathrm{a}}$ 's as a thermodynamic parameter to determine its purity and also to validate the proposed sorption model which adjusts with the species considered in values of $\mathrm{p} K_{\mathrm{a}}$.

Due to previous results obtained by MALDI-ToF MS [24], it was found that Cy-3-glucoside is a component of the main fraction collected in the purification by HPLC from the semipurified anthocyanin extract. And given the complexity of the real system, it was decided to calculate the experimental acidity constants of the anthocyanin purified by the proposed method.

In spectra that were obtained for each solution (Figure 6) a hypochromic effect was observed in the 500-550 nm maximum absorption while the $\mathrm{pH}$ value increases. In addition there are changes in absorption bands in the UV region.

For solutions at $\mathrm{pH} 4, \mathrm{HCl} 1 \mathrm{~mol} \mathrm{~L}^{-1}$ was added until the flavylium ion was obtained again (red color). However, it was observed that the color change was not reversible in solutions with a $\mathrm{pH} 8$ or more, thus these data were not considered in acidity constants calculations.

The information processing was carried out in the first place by calculating the number of species that absorb by TRIANG, which is a FORTRAN-based program that determines the most probable number of chemical species that absorb electromagnetic radiation from an array of absorbance at different wavelengths. In general terms, TRIANG is the best strategy to find the number for linearly independent equations. Its algorithm is based on the fact that the matrix of absorptions is reduced to a triangular form and compared with the matrix of absorption errors, which in turn is reduced also to a triangular form. The triangular error matrix is constructed from the value of the error in the transmittance $(\Delta T)$ and error propagation equation [30].

The number of species that the program reports is dependent on the value of $\Delta T$, which must be evaluated from the errors involved in the preparation of solutions and the instruments by applying the theory of error propagation. Considering a $\Delta T$ from 0.003 to $0.006\left(\Delta T_{\text {spectrophotometer }}=\right.$ 0.003 ) and obtaining a number of species of four in the interval of $\mathrm{pH} 1-7$ only 3 equilibriums were considered in the refinement of the equilibrium constants by means of the SQUAD program [31]. 


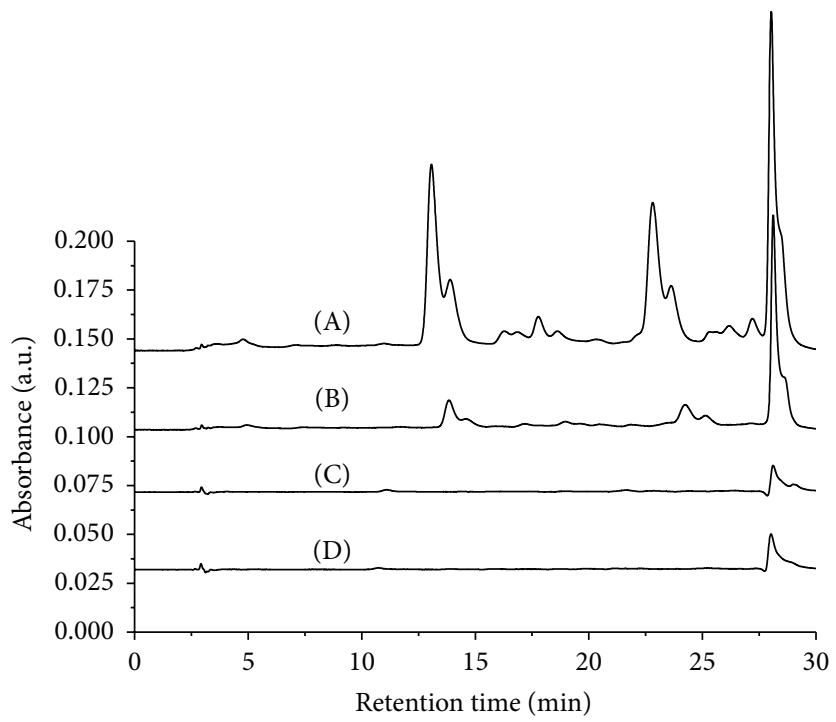

FIGURE 5: Chromatograms obtained from each one of the fractions of the adsorption process. (A) Extract at pH 5 with acetate buffer. (B) Nonretained fraction. (C) Eluted fraction with $\mathrm{NaOH} 0.1 \mathrm{~mol} \mathrm{~L}^{-1}$. (D) Eluted fraction with $\mathrm{HCl} 0.1 \mathrm{~mol} \mathrm{~L}^{-1}$.

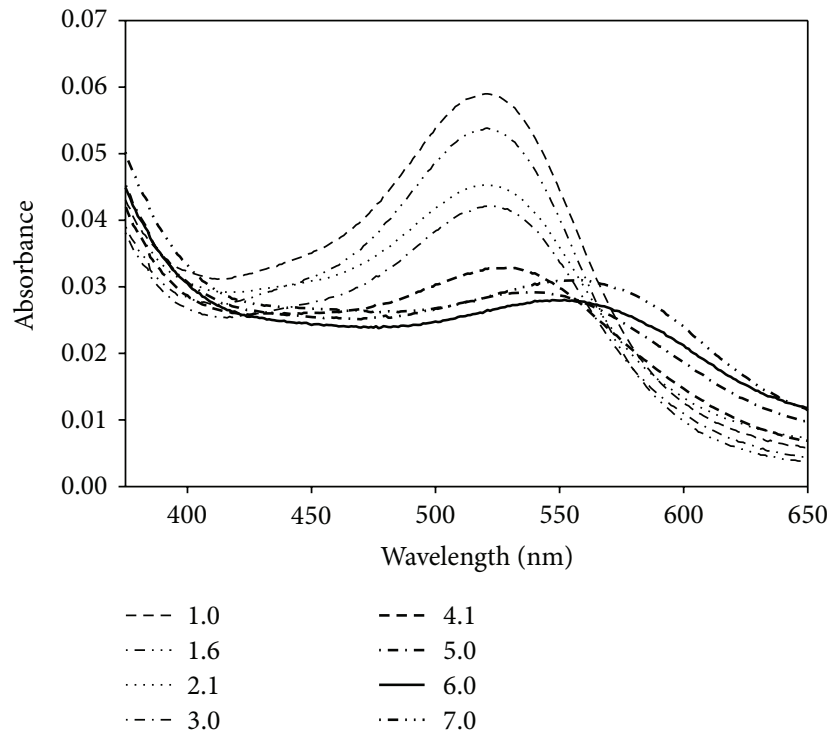

FIGURE 6: UV-vis absorption spectra for the eluted fraction with $\mathrm{HCl} 0.1 \mathrm{~mol} \mathrm{~L}^{-1}$ of the sorption experiment at $\mathrm{pH} 5$, in the range $375-650 \mathrm{~nm}$.

SQUAD (stability quotients from absorbance data) is a FORTRAN-based program designed to perform a calculation of the best values for the stability constant from $\mathrm{pH}$ spectrophotometric titration data. In the analysis of multicomponent spectra the Beer-Lambert law and the law of an absorbance's additivity are assumed to hold. It calculates the best values for the stability constants and molar absorptivity for the proposed model. Besides, various acid-base equilibria mixed-metal and/or mixed ligand complexes can also be studied, and the program can be used for a treatment of absorbance data from non-aqueous as well as from aqueous media [32].

The program can perform a refining of the resulting data for the stability constants for a general complex $\mathrm{M}_{p} \mathrm{~L}_{q} \mathrm{H}_{j}$, where $p, q \gg 0$ and $j$ is positive (for protons), negative (for hydroxide ions), or zero respectively, and by employing a nonlinear least-squares approach. The data fed to the program is the absorbance spectra, a chemical composition (total concentration of $\mathrm{M}, \mathrm{L}$ and $\mathrm{pH}$ ), and a chemical model to describe the system. SQUAD computes the values of the overall stability constants which minimize the sum of the squared residuals between the observed and calculated absorbance values, as follows:

$$
U=\sum_{k=1}^{q} \sum_{\lambda=1}^{m}\left(A_{k}^{\operatorname{exper}(\lambda)}-A_{k}^{\operatorname{calc}(\lambda)}\right)^{2} .
$$

For the constants refinement, a spectral region from 305 to $600 \mathrm{~nm}$ was covered, at intervals of $7 \mathrm{~nm}$. The values of 
these refined constants were $\mathrm{p} K_{\mathrm{a} 1}=1.59(0.19), \mathrm{p} K_{\mathrm{a} 2}=3.94$ (0.15), and $\mathrm{p} K_{\mathrm{a} 3}=6.73(0.11)$.

Results obtained are very similar to those found for the Cy-3-glucoside standard by Moncada and coworkers [25], whose values are $\mathrm{p} K_{\mathrm{a} 1}=1.85, \mathrm{p} K_{\mathrm{a} 2}=3.34$, and $\mathrm{p} K_{\mathrm{a} 3}=6.60$. These results are also different from the constants reported for Malvidin-3-glucoside, whose $\mathrm{p} K_{\mathrm{a}}$ 's reported are $\mathrm{p} K_{\mathrm{a} 1}=$ $1.76 \pm 0.07, \mathrm{pK}_{\mathrm{a} 2}=5.36 \pm 0.04$ and $\mathrm{p} K_{\mathrm{a} 3}=8.39 \pm 0.07$ [33]. In addition, the o-dihydroxy arrangement is not present. The differences between the constants calculated in this work and the ones reported previously are attributed to the lack of control of neither the temperature nor the ionic strength $(\mu)$.

These facts apparently confirm that the anthocyanin that forms the complex with $\mathrm{Fe}^{3+}$ present in the extract is the Cy-3-glucoside, in addition to covering the complexation requirement that is the o-dihydroxy arrangement in the $\mathrm{B}$ aromatic ring.

\section{Conclusions}

The proposed Cy-3-glucoside purification method by means of sorption in cationic exchange resin loaded with $\mathrm{Fe}^{3+}$ is shown to be quite viable for o-dihydroxy anthocyanins, because of the following.

(1) It decreases procedure costs, since it is possible to be carried out in less time unlike the chromatographic methods proposed previously.

(2) The percentage of anthocyanin extraction reached is above $99.99 \%$.

(3) It is possible to collect the main anthocyanin with high purity and analyze it by other spectroscopic techniques.

\section{Conflict of Interests}

The authors declare that there is no conflict of interests regarding the publication of this paper.

\section{Acknowledgment}

The authors acknowledged SNI (CONACyT) for the stipend received.

\section{References}

[1] A. Castañeda-Ovando, M. L. Pacheco-Hernández, M. E. PáezHernández et al., "Chemical studies of anthocyanins: a review," Food Chemistry, vol. 113, no. 4, pp. 859-871, 2009.

[2] I. Konczak and W. Zhang, "Anthocyanins-more than nature's colours," Journal of Biomedicine and Biotechnology, vol. 2004, no. 5, pp. 239-240, 2004.

[3] M. M. Giusti and R. E. Wrolstad, "Unit F1.2.1-13. Anthocyanins. Characterization and measurement of anthocyanins by UVVisible spectroscopy," in Current Protocols in Food Analytical Chemistry, E. R. Wrolstad, Ed., John Wiley \& Sons, New York, NY, USA, 2001.

[4] E.-S. M. Abdel-Aal, J. C. Young, and I. Rabalski, "Anthocyanin composition in black, blue, pink, purple, and red cereal grains,"
Journal of Agricultural and Food Chemistry, vol. 54, no. 13, pp. 4696-4704, 2006.

[5] D. Kammerer, J. Gajdos Kljusuric, R. Carle, and A. Schieber, "Recovery of anthocyanins from grape pomace extracts (Vitis vinifera L. cv. Cabernet Mitos) using a polymeric adsorber resin," European Food Research and Technology, vol. 220, no. 3-4, pp. 431-437, 2005.

[6] J. Lee, R. W. Durst, and R. E. Wrolstad, "Impact of juice processing on blueberry anthocyanins and polyphenolics: comparison of two pretreatments," Journal of Food Science, vol. 67, no. 5, pp. 1660-1667, 2002.

[7] M. P. Kähkönen, A. I. Hopia, and M. Heinonen, "Berry phenolics and their antioxidant activity," Journal of Agricultural and Food Chemistry, vol. 49, no. 8, pp. 4076-4082, 2001.

[8] M. R. Coutinho, M. B. Quadri, R. F. P. M. Moreira, and M. G. N. Quadri, "Partial purification of anthocyanins from Brassica oleracea (red cabbage)," Separation Science and Technology, vol. 39, no. 16, pp. 3769-3782, 2004.

[9] H. Donner, L. Gao, and G. Mazza, "Separation and characterization of simple and malonylated anthocyanins in red onions, Allium cepa L.," Food Research International, vol. 30, no. 8, pp. 637-643, 1997.

[10] A. Romani, N. Mulinacci, P. Pinelli, F. F. Vincieri, and A. Cimato, "Polyphenolic content in five tuscany cultivars of Olea europaea L.," Journal of Agricultural and Food Chemistry, vol. 47, no. 3, pp. 964-967, 1999.

[11] T. Fossen and $\varnothing$. M. Andersen, "Anthocyanins from red onion, Allium cepa, with novel aglycone," Phytochemistry, vol. 62, no. 8, pp. 1217-1220, 2003.

[12] M. Schwarz, S. Hillebrand, S. Habben, A. Degenhardt, and P. Winterhalter, "Application of high-speed countercurrent chromatography to the large-scale isolation of anthocyanins," Biochemical Engineering Journal, vol. 14, no. 3, pp. 179-189, 2003.

[13] A. M. Vivar-Quintana, C. Santos-Buelga, and J. C. RivasGonzalo, "Anthocyanin-derived pigments and colour of red wines," Analytica Chimica Acta, vol. 458, no. 1, pp. 147-155, 2002.

[14] L. Gao and G. Mazza, "Quantitation and distribution of simple and acylated anthocyanins and other phenolics in blueberries," Journal of Food Science, vol. 59, no. 5, pp. 1057-1059, 1994.

[15] B. Berente, D. de la Calle García, M. Reichenbacher, and K. Danzer, "Method development for the determination of anthocyanins in red wines by high-performance liquid chromatography and classification of German red wines by means of multivariate statistical methods," Journal of Chromatography A, vol. 871, pp. 95-103, 2000.

[16] J. A. Kennedy and A. L. Waterhouse, "Analysis of pigmented high-molecular-mass grape phenolics using ion-pair, normalphase high-performance liquid chromatography," Journal of Chromatography A, vol. 866, no. 1, pp. 25-34, 2000.

[17] E. Mataix and M. D. Luque De Castro, "Determination of anthocyanins in wine based on flow-injection, liquid-solid extraction, continuous evaporation and high-performance liquid chromatography-photometric detection," Journal of Chromatography A, vol. 910, no. 2, pp. 255-263, 2001.

[18] N. A. Nyman and J. T. Kumpulainen, "Determination of anthocyanidins in berries and red wine by high-performance liquid chromatography," Journal of Agricultural and Food Chemistry, vol. 49, no. 9, pp. 4183-4187, 2001.

[19] C. Alcalde-Eon, M. T. Escribano-Bailón, C. Santos-Buelga, and J. C. Rivas-Gonzalo, "Separation of pyranoanthocyanins from red wine by column chromatography," Analytica Chimica Acta, vol. 513, no. 1, pp. 305-318, 2004. 
[20] C. T. da Costa, D. Horton, and S. A. Margolis, "Analysis of anthocyanins in foods by liquid chromatography, liquid chromatography-mass spectrometry and capillary electrophoresis," Journal of Chromatography A, vol. 881, no. 1-2, pp. 403-410, 2000.

[21] R. Boulton, "The copigmentation of anthocyanins and its role in the color of red wine: a critical review," American Journal of Enology and Viticulture, vol. 52, pp. 67-87, 2001.

[22] K. Yoshida, S. Kitahara, D. Ito, and T. Kondo, "Ferric ions involved in the flower color development of the Himalayan blue poppy, Meconopsis grandis," Phytochemistry, vol. 67, no. 10, pp. 992-998, 2006

[23] M. T. Escribano-Bailón, C. Santos-Buelga, and J. C. RivasGonzalo, "Anthocyanins in cereals," Journal of Chromatography A, vol. 1054, no. 1-2, pp. 129-141, 2004.

[24] A. Castañeda-Ovando, C. A. Galán-Vidal, L. Pacheco, J. A. Rodriguez, and M. E. Páez-Hernández, "Characterization of main anthocyanins extracted from pericarp blue corn by MALDI-ToF MS," Food Analytical Methods, vol. 3, no. 1, pp. 12$16,2010$.

[25] M. C. Moncada, S. Moura, M. J. Melo, A. Roque, C. Lodeiro, and F. Pina, "Complexation of aluminum(III) by anthocyanins and synthetic flavylium salts: a source for blue and purple color," Inorganica Chimica Acta, vol. 356, pp. 51-61, 2003.

[26] K. L. Hale, S. P. McGrath, E. Lombi et al., "Molybdenum sequestration in Brassica species. A role for anthocyanins?" Plant Physiology, vol. 126, no. 4, pp. 1391-1402, 2001.

[27] J. A. Muñoz, A. Gonzalo, and M. Valiente, "Arsenic adsorption by Fe(III)-loaded open-celled cellulose sponge. Thermodynamic and aelectivity aspects," Environmental Science \& Technology, vol. 36, pp. 3405-3411, 2002.

[28] I. Rau, A. Gonzalo, and M. Valiente, "Arsenic(V) adsorption by immobilized iron mediation: modeling of the adsorption process and influence of interfering anions," Reactive and Functional Polymers, vol. 54, no. 1-3, pp. 85-94, 2003.

[29] Dow, "DOWEX Ion Exchange Resins: using ion exchange resin selectivity coefficients," Dow, Midland, Mich, USA, 2008.

[30] F. R. Hartley, C. Burgess, and C. R. M. Alcock, Solution Equilibria, Ellis Horwood, New York, NY, USA, 1980.

[31] D. J. Leggett and W. A. E. McBryde, "General computer program for the computation of stability constants from absorbance data," Analytical Chemistry, vol. 47, no. 7, pp. 1065-1070, 1975.

[32] D. J. Leggett, Computational Methods for the Determination of Formation Constants, Plenum Press, New York, NY, USA, 1985.

[33] R. E. Asenstorfer, P. G. Iland, M. E. Tate, and G. P. Jones, "Charge equilibria and pKa of malvidin-3-glucoside by electrophoresis," Analytical Biochemistry, vol. 318, no. 2, pp. 291-299, 2003. 

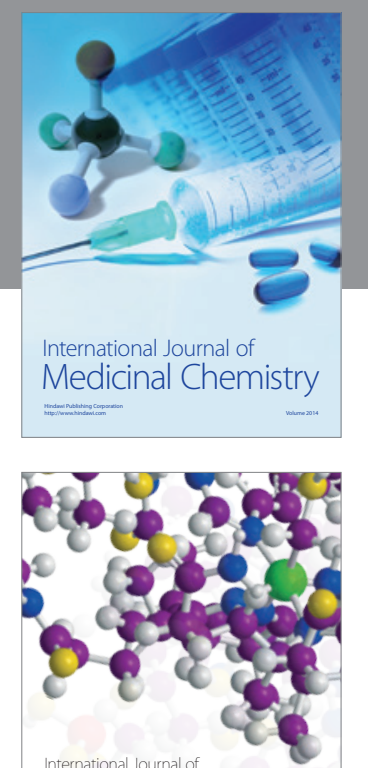

\section{Carbohydrate} Chemistry

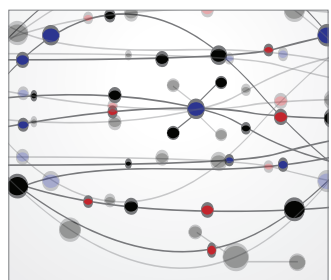

The Scientific World Journal
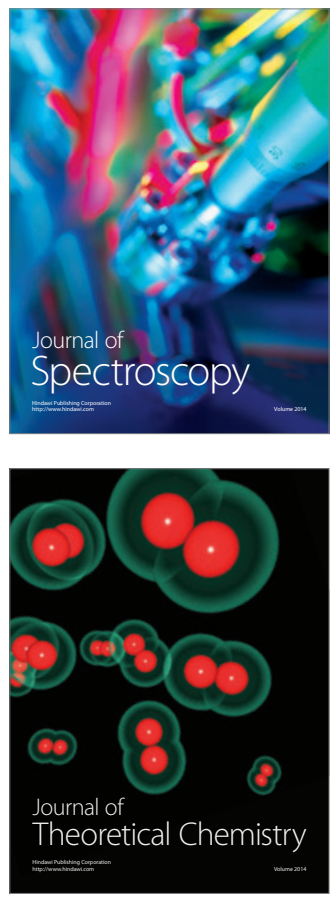
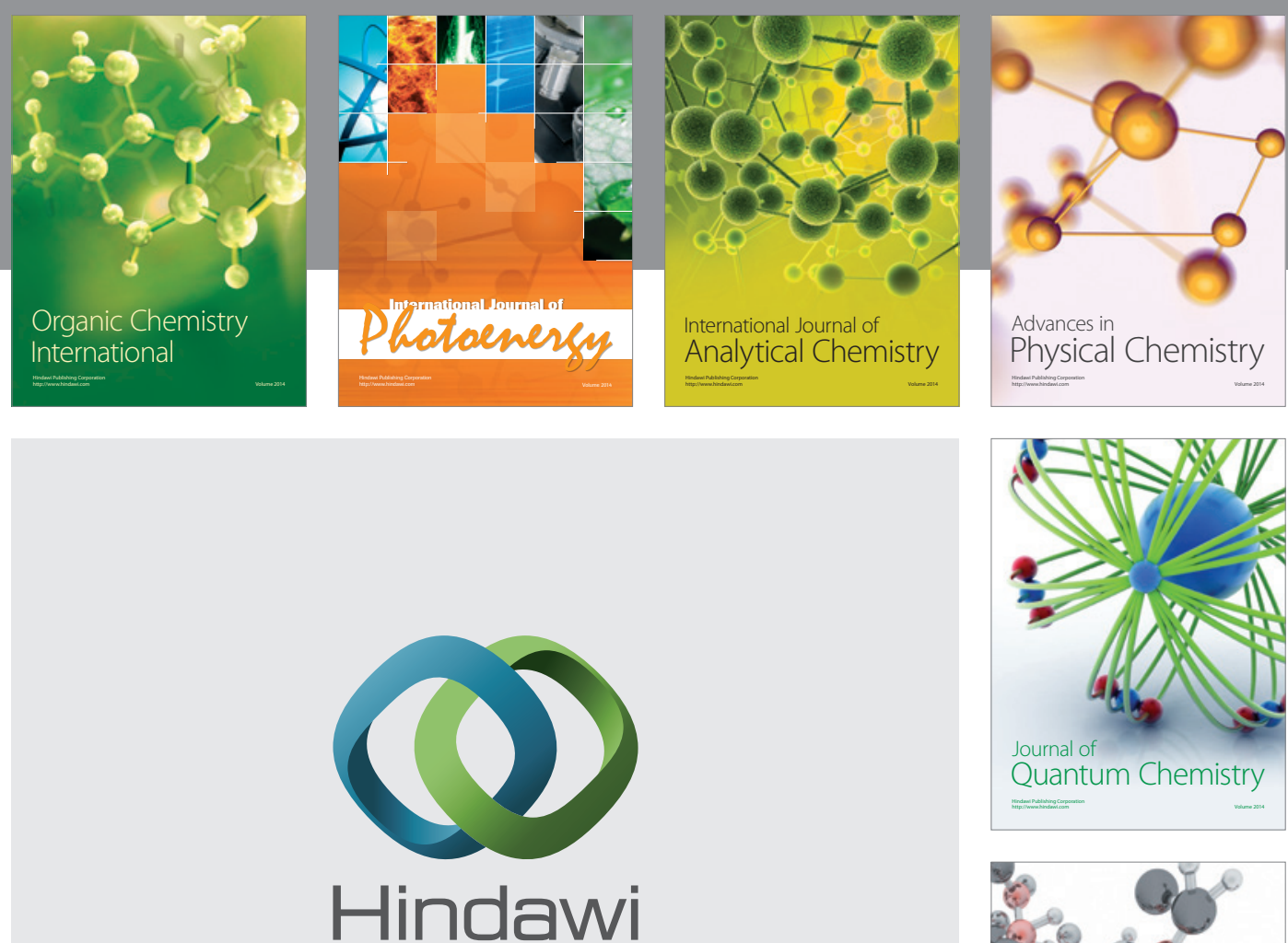

Submit your manuscripts at

http://www.hindawi.com

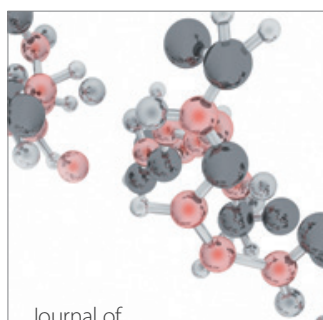

Analytical Methods

in Chemistry

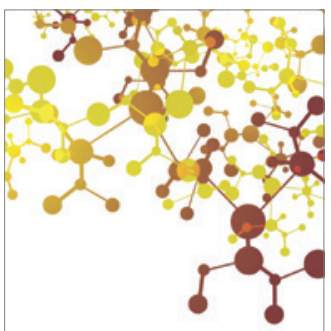

Journal of

Applied Chemistry

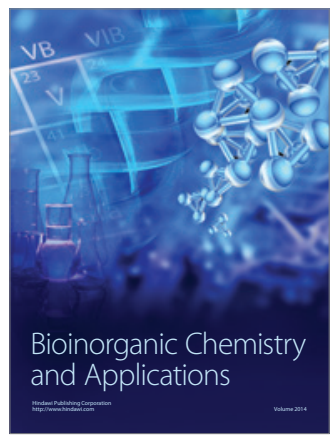

Inorganic Chemistry
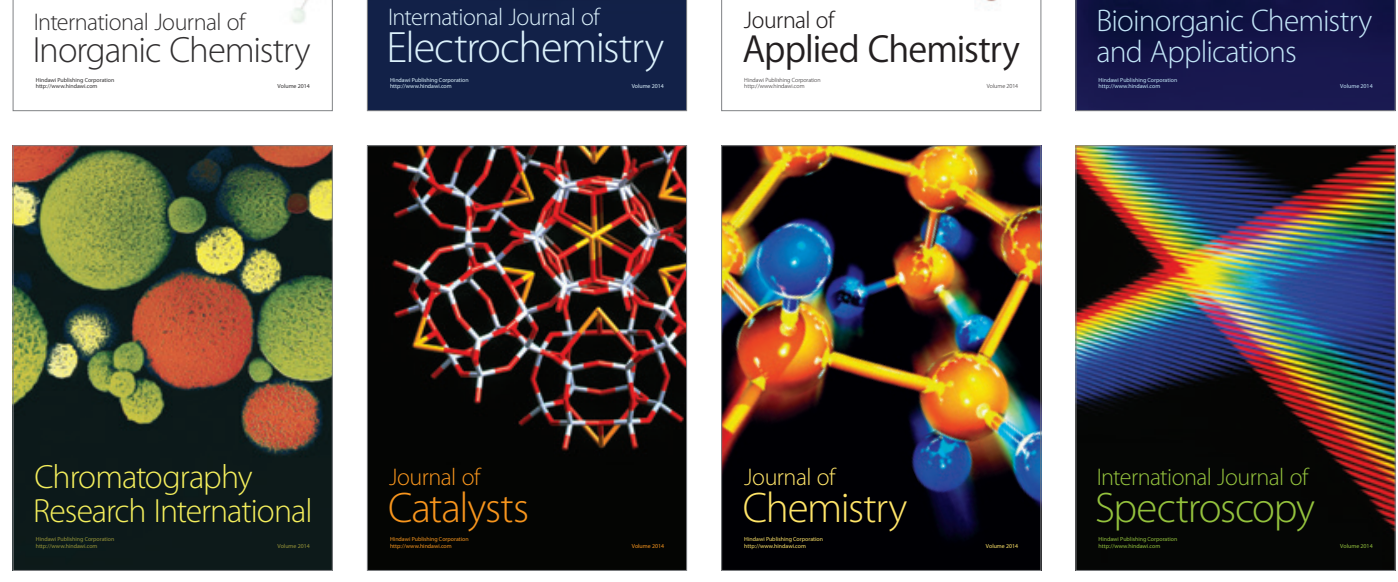